\title{
AULAS DE EDUCAÇÃO FÍSICA DE PRÉ A QUARTA SÉRIE NAS ESCOLAS MUNICIPAIS: AVALIAÇÃO DE UMA PROPOSTA ${ }^{1}$
}

\author{
GORI, Renata Machado de Assis - Mestre em Educação/UFMG - Docente EF/CAJ/UFG \\ renata@jatainet.com.br \\ AZEVEDO, Sílvia Helais de - Acadêmica do $4^{\circ}$ ano - EF/CAJ/UFG \\ SOARES, Karla Ferreira - Acadêmica do $2^{\circ}$ ano - EF/CAJ/UFG
}

RESUMO: Este artigo é produto da investigação realizada, com fins avaliativos, sobre o processo de implantação e execução da proposta de Educação Física na Educação Infantil e nas séries iniciais do Ensino Fundamental (primeira a quarta), ministrada por um professor licenciado em Educação Física, na rede municipal de ensino de Jataí-GO. A intenção foi verificar os motivos que levaram à suspensão das aulas ministradas pelo professor de Educação Física nas referidas séries, retornando ao sistema de unidocência. A presença do profissional qualificado parece ser uma discussão superada no meio acadêmico, dado sua inegável relevância, comprovada cientificamente. No entanto, esta realidade distoante requer uma avaliação contextualizada, desde a implantação da proposta em 2001 até a suspensão das aulas arbitrariamente em 2003. O estudo qualitativodescritivo envolveu 370 sujeitos das escolas municipais e da Secretaria Municipal de Educação. Os instrumentos utilizados foram o formulário e a entrevista semi-estruturada. A relevância deste trabalho de investigaçãoavaliação é a possibilidade de repensar a presença de um profissional específico para ministrar aulas de Educação Física nas escolas públicas, de pré a quarta série, e a partir dos dados coletados buscar alternativas para a viabilização das vivências corporais lúdicas na infância, dentro deste espaço educacional, e para o preparo dos profissionais aos quais esta tarefa for designada, através da educação continuada, independente de seu curso de formação inicial (Pedagogia, Educação Física, etc.). A intenção ao propor este tipo de pesquisa foi de que a administração municipal, bem como a população de Jataí e de outras regiões do país, que passam por experiências semelhantes possam ter um diagnóstico da atual situação em que a Educação Física se encontra, dentro das escolas da rede, e das necessidades e dificuldades que esta disciplina vem enfrentando, desde a implantação da proposta. Não foi alvo deste estudo propor soluções para os problemas detectados, mas suscitar discussões sobre a viabilização de participação em atividades motoras pelas crianças que se encontram em fase de desenvolvimento e estão matriculadas nas escolas.

Palavras-Chave: Escola - Ensino Fundamental - Professor de Educação Física

\begin{abstract}
This article is product of the accomplished investigation, with ends of evaluation, about the elaboration process and execution of the proposal of Physical Education in the Infantile Education and in the initial series of the Fundamental Teaching (first to fourth), accomplished for a licensed teacher in Physical Education, in the municipal net of teaching of Jataí-GO. The intention went verify the reasons that took to the suspension of the classes accomplished for the teacher of Physical Education in referred them series, coming back to the an only teacher system. The qualified professional's presence seems to be a discussion overcome in the academic, given middle its undeniable relevance, checked scientifically. However, this reality different requests an evaluation contextualizada, from the elaboration of the proposal in 2001 to the suspension of the classes arbitrarily in 2003. The qualitative-descriptive study involved 370 subject of the municipal schools and of the Municipal Clerkship of Education. The used instruments went the form and to semi-structured interview. The relevance of this investigation-evaluation work is the possibility to rethink the a specific professional's presence for accomplished classes of Physical Education in the public schools, of Infantile Education the fourth serie, and starting from the collected data to look for alternatives for the viabilização of the existences recreational corporal experiences in the childhood, inside of this educational space, and for the prepare of the professionals to the which this task be designated, through the continuous education, independent of its course of initial formation (Pedagogy, Physical Education, etc.). The intention when proposing this research type went that to municipal administration, as well as the population of Jataí and of other areas of the country, that go by similar experiences, they can have a diagnosis of the current situation in that the Physical Education meets, inside of the schools of the net, and of the needs and difficulties that this discipline comes facing, from the elaboration of the proposal. It was not white of this study to propose solutions for the detected problems, but to
\end{abstract}

\footnotetext{
${ }^{1}$ Esta pesquisa foi realizada por uma docente e duas alunas do Curso de Educação Física do Campus Avançado de Jataí-Universidade Federal de Goiás, no ano de 2004, com uma bolsa concedida pela Superintendência Municipal de Ciência e Tecnologia da Prefeitura Municipal de Jataí-Goiás (SMCT).
} 
raise discussions about to make possible the participation in motive activities for the children that meet in development phase and are registered in the schools.

Word-Key: School - Teach Fundamental - Teacher of Physical Education

Introdução

Ao escrever e publicar este artigo tivemos como objetivo principal divulgar os resultados da pesquisa realizada no ano de 2004, intitulada “Aulas de Educação Física de pré a quarta série nas escolas municipais: avaliação de uma proposta”. É importante que se conheça a realidade das escolas públicas, no que se refere à presença de um professor específico para ministrar aulas de Educação Física para as séries iniciais. As informações coletadas, através de ampla investigação de campo e bibliográfica, foram analisadas e discutidas de forma contextualizada e fundamentada. O produto deste processo será, portanto, apresentado de forma resumida, em três momentos.

Inicialmente será feita uma contextualização da pesquisa, apresentando pontos que desencadearam a necessidade de investigar sobre este objeto de estudo. Serão apontadas, ainda, as metas estabelecidas e a metodologia adotada. Em seguida os resultados encontrados serão organizados e expostos de modo a deixar fluir a voz dos sujeitos envolvidos nesta investigação. Finalmente, serão tecidas algumas considerações sobre a realidade detectada, organizando as informações em itens objetivos e sintéticos, para facilitar a compreensão de um assunto tão extenso e polêmico, que culmina na clássica pergunta: "Quem deve dar as aulas de Educação Física?”

\section{Desvelando uma realidade: contextualização da investigação}

A forma como as aulas de Educação Física vinham acontecendo nas escolas municipais em Jataí-GO, de pré a quarta série, trouxe preocupações a uma equipe de quatro professoras do curso de Educação Física do CAJ/UFG e dois colaboradores (egressos deste mesmo curso), que se reuniram, no intuito de elaborar uma proposta de intervenção para o ensino desta disciplina, que deveria ser ministrada por um professor específico, com qualificação na área. A implantação da referida proposta ocorreu no início do ano letivo de 2001 e o trabalho foi realizado até o final do ano de 2003, sob a coordenação de um professor escolhido pela equipe e que participou de todo o processo - de discussão inicial, elaboração, implantação, acompanhamento da proposta e avaliação informal.

O objetivo geral da proposta de Educação Física foi implantar as aulas desta disciplina na rede municipal de ensino de Jataí-GO, nas séries já especificadas, ministradas 
por professores qualificados na área, respeitando as necessidades discentes $\mathrm{e}$ as especificidades contextuais. Para isto, além do coordenador específico, foram contratados professores licenciados em Educação Física e que haviam sido aprovados em concurso público, e outros professores, igualmente qualificados, que firmaram contrato especial por tempo determinado. As aulas começaram a ser ministradas no ano de 2001 e apenas algumas escolas da rede municipal não foram contempladas, neste primeiro ano, com a inserção do professor de Educação Física nas séries iniciais, por número insuficiente de docentes.

O desenvolvimento da proposta se deu de forma bastante regular, apesar de algumas dificuldades, tais como a estrutura física e material para a realização das aulas e ainda o relacionamento na escola, proveniente do descompromisso com suas tarefas por parte de um ou outro professor. No entanto, no início do corrente ano, houve uma suspensão das aulas ministradas pelos profisssionais de Educação Física nas escolas municipais, de pré a quarta série, mesmo tendo sido realizado novo concurso para contratação de pessoal para atuar nesta função, nesse mesmo período.

Diante deste fato inédito, surgiu a inquietação quanto à relevância da presença $\mathrm{e}$ atuação do profissional de Educação Física no contexto escolar municipal. Decidimos, então, realizar uma ampla avaliação da implantação da proposta, através dos relatos dos professores de Educação Física, professores das outras áreas, diretores, coordenadores, servidores e alunos das escolas e funcionários da Secretaria Municipal de Educação que participaram deste momento (especificamente de 2001 a 2003), observando prioritariamente os seguintes aspectos: dificuldades encontradas no processo de implantação da nova proposta; contribuições que a prática de Educação Física, ministrada por um professor qualificado, trouxe à escola; situações de convivência nos momentos coletivos (positivos e negativos).

A presença da Educação Física na escola é importante, principalmente na Educação Infantil e nas séries iniciais do Ensino Fundamental, como evidenciam COLETIVO DE AUTORES (1993) e FREIRE (1992), dentre outros. A Educação Física na escola pode se constituir em tempo e lugar de investigação e problematização da história de alunos e alunas presentes na escola, que revela o conhecimento sobre as práticas corporais da cultura de que são portadores(as); de questionamento de padrões éticos e estéticos previamente construídos; de invenção de outras formas de fazer os esportes, as danças, a ginástica, os jogos, as lutas, os brinquedos e as brincadeiras; de criação e recriação de práticas corporais da cultura; de garantia do direito de participação, sem exclusão por nenhum motivo; e de respeito à corporeidade individual, construída em sua história de vida. Em síntese, a Educação Física objetiva desenvolver a postura crítica dos alunos perante as atividades da cultura corporal, no 
sentido da aquisição de autonomia de conhecimentos/habilidades necessários a uma prática intencional e permanente, considerando o lúdico e os processos sócio-comunicativos no sentido do prazer, da auto-realização e da qualidade de vida (VAGO, 1999; JEBER, 1997).

A prática de atividades físicas na escola, mais especificamente, a disciplina Educação Física escolar, é garantida pela LDB, sendo obrigatória em todos os níveis de ensino e facultativa nos cursos noturnos (BARRETO, 1997). No entanto, a unidocência que prevalecia nas séries iniciais de escolarização, antes da implantação da proposta, geralmente não atendia à carga horária que lhe era destinada (freqüência e duração semanal), conforme dados encontrados por SILVEIRA (1999). Os unidocentes enfrentam muitas dificuldades ao desenvolver as atividades inerentes a esta disciplina, principalmente pela falta de preparo (qualificação e respaldo bibliográfico), o que faz com que os professores de sala de aula defendam, segundo o autor, a presença de um profissional qualificado para atender aos alunos.

A relevância deste trabalho de investigação-avaliação é a possibilidade de repensar a presença de um profisssional específico para ministrar aulas de Educação Física nas escolas públicas, de pré a quarta série, e a partir dos dados coletados buscar alternativas para a viabilização das vivências corporais lúdicas na infância, dentro deste espaço educacional, e para o preparo dos profissionais aos quais esta tarefa for designada, através da educação continuada, independente de seu curso de formação inicial (Pedagogia, Educação Física, etc.).

A intenção ao propor este tipo de pesquisa foi de que a administração municipal, bem como a população de Jataí e de outras regiões do país, que passam por experiências semelhantes, possam ter um diagnóstico da atual situação em que a Educação Física se encontra, dentro das escolas da rede, e das necessidades e dificuldades que esta disciplina vem enfrentando, desde a implantação da proposta. Não foi alvo deste estudo propor soluções para os problemas detectados, mas suscitar discussões sobre a viabilização de participação em atividades motoras pelas crianças que se encontram em fase de desenvolvimento e estão matriculadas nas escolas.

Algumas indagações ultrapassam os objetivos deste processo investigativo, mas constituem-se em possibilidades para outras buscas que venham a complementar nosso trabalho: Quem deve ministrar as aulas de Educação Física escolar? Que conteúdos devem ser priorizados nestas aulas? O que se deve fazer para incrementar o preparo didático-pedagógico do profissional que irá lidar com esta disciplina na escola?

Sinteticamente, o objetivo geral desta pesquisa foi investigar com fins avaliativos o processo de implantação e execução da proposta de Educação Física na Educação Infantil e 
nas séries iniciais do Ensino Fundamental (primeira a quarta), ministrada por um licenciado em Educação Física, através dos relatos de sujeitos que integram o coletivo escolar e que participaram deste momento, buscando informações sobre as dificuldades e benefícios que esta inovação trouxe às escolas da rede municipal de ensino de Jataí-GO.

Para que este objetivo fosse alcançado, estabelecemos algumas metas.

- Averiguar as dificuldades encontradas no processo de implantação e execução da proposta de Educação Física.

- Elencar as possíveis contribuições que a prática de Educação Física, ministrada por um professor qualificado, trouxe à escola.

- Verificar como aconteciam os momentos de convivência do coletivo da escola, tanto de trabalho quanto de lazer, listando situações positivas e negativas.

- Investigar a opinião dos sujeitos que tiveram participação direta e indireta nesta experiência, com relação a "quem deve ministrar as aulas de Educação Física de pré á quarta série" nas escolas municipais.

- Suscitar posteriores discussões sobre a temática investigada, com vistas a contribuir na busca de alternativas para a realização de um ensino com maior qualidade para a rede municipal de Jataí-GO e de outras cidades que possuem contexto semelhante.

Para a realização desta pesquisa junto à rede municipal de ensino de Jataí, optamos por realizar um estudo qualitativo, do tipo descritivo, que envolveu todas as escolas que tiveram turmas de pré à quarta série freqüentando aulas de Educação Física, ministradas por um professor licenciado nesta área, entre o período correspondente à implantação e suspensão das aulas desta disciplina, que vai do início de 2001 ao final de 2003.

Inicialmente procedemos a um levantamento exploratório sobre a realidade das escolas, através da Secretaria Municipal de Educação (SME), visando obter informações sobre: número de estabelecimentos de ensino que participaram da experiência, seu nome e localização (endereço); nome das pessoas pertencentes ao quadro administrativo das escolas, durante este período; nome dos professores de Educação Física que trabalharam na rede de ensino municipal com as turmas de pré à quarta série, concursados e contratados, e as respectivas escolas nas quais atuaram; endereço e telefone de todos os professores de Educação Física e pessoal da administração escolar, os já desligados da SME e os que estão 
em exercício, viabilizando os contatos; turmas e escolas que não foram atendidas com a implantação da proposta; e outros dados, conforme a necessidade.

Dentre vinte e nove escolas existentes na rede municipal de ensino, dezoito foram escolhidas como local de investigação, visto terem oferecido aulas de Educação Física de pré a quarta série, ministradas por professor licenciado nesta área. Das onze escolas excluídas, sete funcionam na zona rural e duas estão localizadas em povoados vizinhos (Estância e Naveslândia), uma esteve desativada para reforma em 2003 e outra também não teve aulas em 2004 pelo mesmo motivo. A exclusão das escolas rurais e de povoados vizinhos é justificada pelo fato de que não participaram da implantação da proposta, e as escolas que estiveram em reforma sofreram redistribuição do seu quadro de pessoal, o que inviabilizou o contato com os sujeitos.

Após este trabalho inicial, foram escolhidos os sujeitos de pesquisa, cujo primeiro critério utilizado foi a participação direta ou indireta no processo de implantação da proposta de Educação Física nas escolas do município, entre 2001 e 2003. A previsão era de que fossem abordados todos os professores de Educação Física que trabalharam com as séries envolvidas durante este período (integral ou parcial). Em cada escola que sediou as aulas mencionadas, foram selecionados: diretor, coordenadores, no mínimo um funcionário administrativo (da secretaria), dois servidores (que podem ser da limpeza e da merenda), pelo menos um professor de sala de aula e três alunos de cada série (o que totaliza um número mínimo de cinco professores e quinze alunos, visto que são cinco séries ao todo). Na SME foram escolhidos como sujeitos de pesquisa o Secretário Municipal de Educação, que atuou no período mencionado; o coordenador de Educação Física de $1^{\mathrm{a}}$ a $4^{\mathrm{a}}$ série, contratado pela rede municipal de ensino para acompanhar a implantação e a execução da proposta; a chefe da Divisão de Ensino e a chefe do Departamento Pedagógico. O número de sujeitos envolvidos totalizou 370, sendo vinte por escola, em média.

Foi necessário fazer uma alteração no grupo de participantes da pesquisa. Durante as primeiras visitas às escolas, ao preencher os formulários com os alunos de primeira e segunda série, percebeu-se que eles apresentavam dificuldades em se expressar, não tinham segurança em suas respostas e não se lembravam de como haviam acontecido as aulas de Educação Física no ano anterior. Grande parte não recordava nem mesmo de quem ministrou estas aulas, provavelmente por se tratar de crianças de pouca idade. Diante destas imprecisões, apenas os alunos de terceira e quarta série responderam aos formulários. Como a previsão era de que três alunos por turma respondessem às perguntas, ampliamos este número para seis, em cada série, visando coletar o máximo de opiniões sobre o assunto. Alguns 
coordenadores não quiseram se manifestar dizendo ter convivido pouco com a Educação Física ministrada na escola, no período investigado, mas isto não prejudicou a coleta de dados. O restante dos sujeitos participou conforme o esperado.

$\mathrm{Na}$ intenção de preservar o anonimato destas pessoas, seus nomes foram mantidos em sigilo e cada sujeito recebeu um nome fictício, para que todos pudessem discorrer sobre o tema sem receio de se submeter a qualquer tipo de crítica ou censura.

Tendo em vista o grande público envolvido neste trabalho, um dos instrumentos de pesquisa adotado foi o formulário, conforme já foi mencionado, visto que facilita o acesso às informações objetivamente, contemplando inclusive os sujeitos que têm dificuldade de se expressar por escrito ou que têm receio de responder às indagações diante de um gravador ou filmadora. A entrevista semi-estruturada foi utilizada com quatro sujeitos que ocupavam cargos de chefia na SME, também citados anteriormente. As entrevistas duraram em média trinta minutos, cada uma, e foram gravadas e transcritas integralmente.

Finalmente foram analisados os dados, sob fundamentação do referencial teórico compilado durante todo o processo, e os resultados serão explicitados na segunda parte deste artigo, que se configura como um relatório final de todo o trabalho realizado. ${ }^{2}$

\section{A Educação Física de pré à quarta série: a voz dos sujeitos}

Durante estes nove meses de investigação, foi possível coletar informações sobre o problema levantado através da fala de diferentes indivíduos que participaram do processo de implantação da proposta de Educação Física para as séries iniciais da rede municipal de ensino. Procurando facilitar a visualização destes dados, apresentaremos cinco itens, que emergiram do discurso dos sujeitos.

2.1 Dificuldades encontradas no processo de implantação e execução da proposta

Uma primeira dificuldade apontada foi a falta de estrutura física de algumas escolas municipais, que não dispõem de local apropriado para a prática de Educação Física. A falta de compromisso dos professores desta disciplina foi citada por dezenove sujeitos,

\footnotetext{
${ }^{2} \mathrm{O}$ relatório final do trabalho desenvolvido, conforme acordo firmado no início desta pesquisa, é apresentado ao Conselho Municipal de Ciência e Tecnologia da Prefeitura Municipal de Jataí, através da Superintendência Municipal de Ciência e Tecnologia, contendo todas as informações provenientes das pesquisas de campo e bibliográfica. Este documento apresenta dados referentes à realidade investigada e tem caráter de divulgação, não cabendo propostas de solução para os problemas detectados ou sugestões de intervenção.
} 
enquanto outros mencionaram a ausência dos mesmos nos momentos coletivos, justificando que esta ausência, no entanto, deve-se ao fato de que cada professor precisa atender a mais de uma escola, diminuindo sua disponibilidade de tempo de permanência em cada uma destas escolas.

No que se refere à interação do professor de Educação Física no contexto escolar, a referência predominante é de que este profissional normalmente se mostra participativo, entrosado, alegre e motivado.

Oito alunos se referiram ainda à indisciplina dos próprios colegas, que dificultava a atuação do professor de Educação Física.

\subsection{Contribuições da Educação Física Escolar ministrada por um professor da área}

$\mathrm{Na}$ opinião dos sujeitos, a prática de Educação Física ministrada por um professor qualificado nesta área trouxe algumas contribuições: as aulas foram citadas como dinâmicas, atrativas e motivantes, conseguindo prender a atenção dos alunos; o planejamento das atividades era feito com antecedência e criatividade, evitando cair na rotina; o professor de Educação Física foi mencionado como mais qualificado para atender às necessidades dos alunos e da escola; e a presença atuante deste profissional no contexto escolar viabiliza a aquisição de um maior número de recursos materiais, através da SME.

Há um entendimento de Educação Física escolar em dois pólos, conforme SOUZA JÚNIOR (2001, p.85):

\footnotetext{
Num pólo se reconhecem elementos que indicam um grau de aproximação da compreensão de que a Educação Física é um componente curricular caracterizado como algo à parte, na escola, como uma atividade, no sentido restrito e mecânico do termo, e como algo desconfigurado/desprestigiado diante da função da educação escolar. Num outro pólo, evidencia-se um esforço por distanciar-se de tal compreensão de Educação Física, procurando reconhecer sua contribuição para a formação/reflexão pedagógica do aluno.
}

Os professores de Educação Física, diante destes pólos, na opinião dos autores, apresentam-se em uma situação ora de conformação, consentimento; ora de consenso/mediação, com a conotação do "fazer destituído de um saber"; ora de discordância e resistência a esta compreensão, buscando um fazer crítico-reflexivo. 
O primeiro pólo é o que parece vigorar no contexto escolar, principalmente entre pessoas de outras áreas de formação, que têm, na maioria das vezes, um conhecimento parcial do que é esta disciplina e das suas finalidades enquanto componente curricular. Mesmo considerando que esta disciplina requer um professor habilitado para desenvolvê-la, a concepção de Educação Física que transparece nas respostas dadas é a de uma mera exercitação prático-corporal, ou seja, um fazer por fazer (SOUZA JÚNIOR, 2001, p.86).

\subsection{Relatório das escolas beneficiadas com um professor específico de Educação Física ${ }^{3}$}

No final do ano de 2003, foi solicitado aos estabelecimentos de ensino do município que enviassem um relatório sobre a Educação Física que vinha se desenvolvendo de pré à quarta série, ministrada por um professor habilitado nesta área. Dez escolas encaminharam este relatório formalmente. Dentre elas, uma não teve professor de Educação Física atuando nestas séries, por se tratar de uma escola rural. No entanto, solicitou que fosse providenciado um professor específico para trabalhar com recreação dirigida. As outras nove elogiaram o trabalho dos professores, solicitando que no ano de 2004 a proposta continuasse se desenvolvendo nas escolas.

As justificativas ao defender a continuidade das aulas foram referentes: aos resultados obtidos na disciplina, à complementação do processo de ensino-aprendizagem realizado em sala de aula, às estratégias e conteúdos específicos desenvolvidos, ao preparo dos profissionais ao desempenhar esta função, aos benefícios atingidos pelos alunos que participam das aulas (aprendizagem, cooperação, socialização, auto-estima, etc.), dentre outros.

Uma escola, após falar dos benefícios alcançados com a implantação da proposta, solicitou que houvesse um planejamento mais direcionado aos conteúdos de forma a promover a interdisciplinaridade nas aulas; que a freqüência dos professores fosse rigorosamente cumprida; e que a exigência de disciplina dos alunos fosse mais rígida.

\section{4 "Quem deve dar as aulas de Educação Física?”}

$\mathrm{Na}$ opinião da grande maioria dos sujeitos (318 formulários e 2 entrevistas), o

\footnotetext{
${ }^{3}$ A fonte utilizada para apresentar estas informações foi o arquivo de documentos da SME (Divisão de Ensino), disponibilizado pela chefe deste departamento, e trata-se de relatórios encaminhados oficialmente pelas escolas no referido ano.
} 
responsável pelas aulas de Educação Física deve ser o professor qualificado para isto, que se formou nesta área, por estar melhor preparado para assumir esta função. Segundo os relatos, as aulas ministradas pelos unidocentes, geralmente, apresentam repetição de atividades e, por vezes, nem acontece, devido à prioridade dada aos outros conteúdos de sala de aula.

Houve algumas exceções. Quarenta sujeitos (38 formulários e 2 entrevistas) se referiram ao professor de sala de aula como o mais habilitado para tal função. Oito assinalaram que qualquer professor pode ministrar esta disciplina e dois disseram que ninguém deve trabalhar com a Educação Física, provavelmente por não a considerarem relevante no contexto escolar. Estes dados podem ser visualizados na tabela abaixo.

\begin{tabular}{|c|c|c|c|c|c|c|}
\hline SUJEITOS & $\begin{array}{l}\text { PROF. } \\
\text { SALA } \\
\text { DE } \\
\text { AULA }\end{array}$ & $\begin{array}{l}\text { PROF. } \\
\text { ED. } \\
\text { FÍSICA }\end{array}$ & $\begin{array}{l}\text { QUALQUER } \\
\text { PROFESSOR }\end{array}$ & OUTROS & NINGUÉM & $\begin{array}{l}\mathrm{N}^{\mathrm{o}} \text { TOTAL } \\
\mathrm{DE} \\
\text { SUJEITOS }\end{array}$ \\
\hline DIRETORES & 1 & $\underline{16}$ & $\underline{0}$ & $\underline{0}$ & $\underline{0}$ & 17 \\
\hline COORDENADORES & $\underline{0}$ & $\overline{8}$ & $\underline{0}$ & $\underline{\overline{0}}$ & $\underline{0}$ & $\overline{8}$ \\
\hline FUNCIONÁRIOS & $\underline{2}$ & $\underline{41}$ & $\underline{2}$ & $\underline{0}$ & $\underline{0}$ & $\underline{45}$ \\
\hline PROFS. DE ED. FÍS. & $\underline{0}$ & $\overline{10}$ & $\underline{0}$ & $\underline{0}$ & $\underline{0}$ & $\overline{10}$ \\
\hline PROFS. DE SALA & $\underline{1}$ & $\underline{74}$ & $\underline{0}$ & $\underline{0}$ & $\underline{0}$ & 75 \\
\hline ALUNOS & $\underline{34}$ & $\underline{169}$ & $\underline{6}$ & $\underline{\underline{0}}$ & $\underline{\underline{2}}$ & 211 \\
\hline $\begin{array}{l}\text { TOTAL } \\
\text { RESPOSTA }\end{array}$ & $\underline{31}$ & $\underline{318}$ & $\underline{8}$ & $\underline{0}$ & $\underline{2}$ & $\lcm{366}$ \\
\hline
\end{tabular}

Os sujeitos entrevistados não aparecem na tabela, mas dois se manifestaram a favor do professor de Educação Física ministrar as aulas desta disciplina e dois acreditam que o professor de sala de aula seja o mais indicado.

MOLINA e MOLINA NETO (2004) consideram que "ministrar" aulas significa refletir com os alunos sobre os conteúdos específicos próprios da disciplina Educação Física escolar. Para isto, é necessário que o professor conheça, além dos conteúdos específicos de forma aprofundada, também os conteúdos da cultura universal acumulada. No entender destes autores, toda proposta político-pedagógica e toda prática educativa estão submetidas a limitações, e isto ocorre também com a Educação Física, que é uma disciplina curricular, como as outras, e que busca contribuir para as transformações social, econômica, cultural e educativa.

Portanto, pensar em um profissional que não foi habilitado especificamente para "ministrar" esta disciplina, trabalhando com conhecimentos adquiridos de forma compactada, geralmente técnica, e normalmente alheios à discussão crítica realizada na área, não parece ser o que se espera da Educação Física escolar. 
2.5 A suspensão das aulas de Educação Física ministradas pelos profissionais da área

Os motivos que levaram à suspensão das aulas de Educação Física de pré à quarta série, ministradas por um profissional da área, são desconhecidos por 201 dos sujeitos abordados, que justificaram não os saber ou, alguns deles, nem responderam. 81 se referiram à contenção de gastos da prefeitura, devolvendo estas aulas aos professores de sala; 50 citaram interesses políticos; e 34 mencionaram a falta de pessoal qualificado.

A causa informada por dois dos sujeitos ligados à administração municipal foi financeira, justificando que a retirada desses profissionais se deu em decorrência da redução de gastos com a folha de pagamento do município. No entanto, os dois outros entrevistados afirmaram que o motivo foi a falta de interesse em que esta proposta continuasse vigorando. Portanto, parece que nem mesmo na SME os verdadeiros motivos estão sendo divulgados, visto que os envolvidos diretamente se contradizem.

\section{Algumas considerações}

Em síntese, algumas reflexões podem ser apontadas sobre a pesquisa realizada. Não podemos dizer que sejam considerações finais, pois esta é uma discussão que está apenas começando. O principal impacto do resultado desta pesquisa espera-se que seja a reavaliação da necessidade da presença do professor de Educação Física atuando de pré à quarta série nas escolas municipais de Jataí-GO.

Os dados coletados apontaram a necessidade da presença de professores de Educação Física preparados, em nível de graduação, para ministrar aulas de recreação às turmas de pré à quarta série nas escolas municipais. Neste caso, é urgente uma revisão na determinação do poder público municipal de retirar os referidos professores das séries iniciais, ao restabelecer o sistema de unidocência. O impacto social, político e educacional exige "repensar" a situação da Educação Física nas escolas, especificamente de pré a quarta série, demandando a reconstituição do quadro docente e, principalmente, re-significando as aulas desta disciplina na escola.

Dentre as principais informações coletadas e analisadas nesta pesquisa, sinteticamente podemos pontuar que:

a) existe interesse das escolas municipais, bem como da maioria de seus integrantes, em manter o professor qualificado na área de Educação Física atuando nesta 
disciplina, de pré à quarta série, sob o argumento de que este profissional possui um melhor preparo para exercer tal função;

b) a maioria das escolas se manifestou favorável à continuidade das aulas de Educação Física ministradas por um professor específico, apontando benefícios que esta prática trouxe à comunidade escolar;

c) o professor de Educação Física foi apontado pela maioria como o mais apto a desenvolver as aulas de pré à quarta série, devido ao seu preparo teórico-metodológico, no entanto alguns dos sujeitos acreditam que esta tarefa deva ser destinada ao professor de sala de aula;

d) os professores de Educação Física geralmente participam dos momentos coletivos da escola de forma dinâmica e motivada e, quando isto não ocorre, existem justificativas tais como a sobrecarga de trabalho e o choque de horários, visto que todos têm que atender a mais de uma escola para atingir sua carga horária semanal de trabalho;

e) alguns problemas foram elencados pelos sujeitos, com relação ao professor de Educação Física, no que se refere à : pontualidade, assiduidade, relacionamento interpessoal, planejamento, participação nos momentos coletivos da escola, domínio da turma, etc.; mas foram casos isolados e, como em toda profissão, também nesta área existem profissionais que têm menor comprometimento com suas atividades e maior dificuldade em exercer suas funções;

f) nem todas as escolas têm estrutura física adequada para a realização das aulas de Educação Física e, em contrapartida, aquelas que participaram da implantação da proposta, tiveram acesso a novos materiais destinados a esta disciplina, viabilizados pela SME;

g) a proposta de Educação Física implantada apresentou alguns problemas e dificuldades na sua execução, no entanto foi vista como benéfica e necessária pela maioria dos sujeitos envolvidos;

h) os motivos que levaram à suspensão das aulas de Educação Física ministradas pelo professor específico nas séries iniciais eram desconhecidos pela maioria dos sujeitos abordados. Dentre os sujeitos entrevistados e que faziam parte da SME (cargos de chefia), as respostas foram contraditórias, demonstrando desconhecimento ou falta de interesse em divulgar os reais motivos que desencadearam este processo.

A presença do professor de Educação Física atuando nas séries iniciais parece ser uma discussão superada, visto sua significação indiscutível. No entanto, a realidade vivenciada pelo município de Jataí se nega a acatar as evidências, comprovadas 
cientificamente, de que o professor de Educação Física atuando nas séries iniciais é uma necessidade.

Enfim, através da realização desta pesquisa, esperamos suscitar novas discussões sobre esta temática, que poderá ter repercussão na organização funcional das escolas da SME de Jataí-GO. A partir do atual momento, quem deverá atuar nesta função, na opinião da administração municipal, e qual será o seu papel?

\section{Referências Bibliográficas}

BARRETO, Luís André (Coord.). Lei de diretrizes e bases da educação nacional. Cadernos de Educação. Brasília, Ano II, n. 3, março. 1997.

COLETIVO DE AUTORES. Metodologia do ensino de educação física. São Paulo: Cortez, 1992.

FREIRE, João Batista. Educação de corpo inteiro: teoria e prática da educação física. São Paulo: Scipione, 1992.

JEBER, Leonardo José. Plano de ensino em Educação Física escolar: um projeto políticopedagógico em ação. In: SOUSA, Eustáquia Salvadora de; VAGO, Tarcísio Mauro (Orgs.) Trilhas \& partilhas: Educação Física na cultura escolar e nas práticas sociais. Belo Horizonte: Cultura, 1997. p. 113-143.

MOLINA, Rosane Maria Kreusburg; MOLINA NETO, Vicente. Educação Física e educação: o espaço pedagógico para localizar a Educação Física e os fundamentos que podem mantê-la na escola. Reflexões sobre algumas possibilidades. In: CAPARRÓZ, Francisco Eduardo; ANDRADE FILHO, Nelson Figueiredo de (Orgs.). Educação Física escolar: política, investigação e intervenção. Vitória: UFES, LESEF: Uberlândia: UFU, NEPECC, 2004. p. 1333.

SILVEIRA, Plínio Souza. A legitimidade da educação física em Jataí- Goiás. Jataí, GO: 1999. Monografia (Licenciatura em Educação Física) - Curso de Educação Física, Campus Avançado de Jataí, Universidade Federal de Goiás, 1999.

SOUZA JÚNIOR, Marcílio. O saber e o fazer pedagógicos da Educação Física na cultura escolar: o que é um componente curricular? In: CAPARRÓZ, Francisco Eduardo (Org.). Educação Física escolar. Vitória, ES: Proteoria, 2001. p. 81-92.

VAGO, Tarcísio Mauro. Início e fim do século XX: maneiras de fazer educação física na escola. Cadernos Cedes. Corpo e educação. Campinas, Ano XIX, n.48, agosto. 1999. p. 3051. 
